Scientific Paper

\title{
Neutron and photon scattering properties of high density concretes used in radiation therapy facilities: A Monte Carlo study
}

\author{
Asghar MESBAHI ${ }^{1,3, a}$, Rezvan KHALDARI ${ }^{2,3}$ \\ ${ }^{1}$ Immunology research center, Tabriz University of Medical Sciences, Tabriz, Iran \\ ${ }^{2}$ Molecular Medicine Research Center, Tabriz University of Medical Sciences, Tabriz, Iran \\ ${ }^{3}$ Medical Physics Department, Medical School, Tabriz University of Medical Sciences, Tabriz, Iran \\ ${ }^{a}$ E-mail address: amesbahi2010@gmail.com,mesbahiiran@yahoo.com
}

(received 16 May 2017; revised 29 July 2017; accepted 1 August 2017)

\begin{abstract}
In the current study the neutron and photon scattering properties of some newly developed high density concretes (HDCs) were calculated by using MCNPX Monte Carlo code. Five high-density concretes including Steel-Magnetite, Barite, Datolite-Galena, Ilmenite-ilmenite, Magnetite-Lead with the densities ranging from $5.11 \mathrm{~g} / \mathrm{cm}^{3}$ and ordinary concrete with density of $2.3 \mathrm{~g} / \mathrm{cm}^{3}$ were studied in our simulations. The photon beam spectra of 4 and $18 \mathrm{MV}$ from Varian linac and neutron spectra of clinical $18 \mathrm{MeV}$ photon beam was used for calculations. The fluence of scattered photon and neutron from all studied concretes was calculated in different angles. Overall, the ordinary concrete showed higher scattered photons and Datolite-Galena concrete $\left(4.42 \mathrm{~g} / \mathrm{cm}^{3}\right)$ had the lowest scattered photons among all studied concretes. For neutron scattering, fluence at the angle of 180 was higher relative to other angles while for photons scattering fluence was maximum at 90 degree. The scattering fluence for photons and neutrons was dependent on the angle and composition of concrete. The results showed that the fluence of scattered photons and neutrons changes with the composition of high density concrete. Also, for high density concretes, the variation of scattered fluence with angle was very pronounced for neutrons but it changed slightly for photons. The results can be used for design of radiation therapy bunkers.
\end{abstract}

Key words: high density concrete; neutron scattering; photon scattering; radiotherapy bunkers; radiation therapy.

\section{Introduction}

For radiation therapy with high energy photons, the radiation shielding necessitates the use of concretes with considerable thickness to prevent radiation exposure of radiotherapy staff and individuals working around a radiation therapy room. Concretes have been a favorite shielding material for building radiation therapy rooms because of availability, lower price and reasonable shielding properties against high energy photons and neutrons. HDCs(HDC) with density higher than 2.45 are frequently used in radiation facilities where the thinner walls are required for construction and shielding purposes. HDCs are made by adding high atomic number elements such as $\mathrm{Fe}, \mathrm{Ba}$, and $\mathrm{Pb}$ into concrete composition [1-13]. The minerals containing these high $\mathrm{Z}$ materials can be used with different concentrations to provide concretes with higher densities. However, in all of newly developed high density concrete, their mechanical and engineering properties should fulfill the acceptable requirements for building construction. The photon and neutron scattering properties influence the patient received whole body dose from scattered photons and neutrons by concretes walls inside a radiation therapy room.
Additionally, the photon and neutron dose received by maze entrance door is significantly impacted by the scattering properties of concretes walls. Studies have reported that about $75 \%$ of the neutrons at the maze entrance of these rooms are scattered neutrons $[14,15]$. Also, the studies have shown the fluence of scattered photons and neutrons per angle by different shielding materials as well as concretes depend on the composition of concretes and used shielding materials. In a study by Mesbahi et al it was indicated that the photoneutron scattering by different HDCs depends considerably on the their composition [16]. Several studies have reported new formulation for HDCs [1,2,4-8,16]. In a recent study by Khaldari et al shielding properties of several newly developed HDCs was calculated by Monte Carlo method [17]. However, the neutron and photon scattering properties of reported concretes remain unknown for the photon and neutron energy spectra used in radiation therapy rooms. In the current study, the scattering properties on some newly developed HDCs were calculated and reported for further application in the design of radiation therapy rooms. 
Table 1. Studied concretes and their compositions.

\begin{tabular}{|c|c|c|c|c|c|c|}
\hline \multirow{3}{*}{ Element } & \multicolumn{6}{|c|}{ Concrete types and density $\left(\mathrm{g} / \mathrm{cm}^{3}\right)$} \\
\hline & $\begin{array}{c}\text { Steel- } \\
\text { magnetite }^{1}\end{array}$ & $\begin{array}{c}\text { Magnetite- } \\
\text { Lead }^{2}\end{array}$ & $\begin{array}{l}\text { Datolite- } \\
\text { Galena }^{3}\end{array}$ & $\begin{array}{l}\text { Ilmenite- } \\
\text { ilmenite }^{4}\end{array}$ & Barite $^{5}$ & Ordinary $^{6}$ \\
\hline & 5.11 & 4.46 & 4.42 & 3.69 & 3.452 & 2.3 \\
\hline $\mathrm{H}$ & 0.026 & 0.008 & 0.039 & 0.023 & 0.020 & 0.0508 \\
\hline $\mathrm{O}$ & 0.802 & 1.671 & 0.770 & 1.419 & 1.132 & 1.322 \\
\hline $\mathrm{Mg}$ & 0.029 & 0.011 & - & 0.006 & 0.015 & 0.0029 \\
\hline $\mathrm{Al}$ & 0.033 & 0.010 & 0.013 & 0.013 & 0.013 & 0.045 \\
\hline $\mathrm{Si}$ & 0.136 & 0.473 & 0.310 & 0.057 & 0.071 & 0.7006 \\
\hline $\mathrm{P}$ & 0.004 & - & - & 0.002 & 0.0003 & - \\
\hline S & 0.003 & 0.007 & 0.357 & 0.003 & 0.360 & - \\
\hline $\mathrm{Ca}$ & 0.201 & 0.379 & 0.509 & 0.196 & 0.227 & 0.098 \\
\hline Mn & 0.003 & - & 0.006 & 0.005 & 0.003 & - \\
\hline $\mathrm{Fe}$ & 3.869 & 1.339 & 0.028 & 1.033 & 0.010 & 0.0148 \\
\hline $\mathrm{Na}$ & - & 0.001 & 0.008 & 0.020 & 0.001 & 0.0349 \\
\hline $\mathrm{K}$ & - & 0.003 & 0.010 & 0.009 & 0.0005 & 0.023 \\
\hline $\mathrm{C}$ & - & 0.026 & - & - & 0.012 & - \\
\hline $\mathrm{Pb}$ & - & 0.675 & 2.303 & - & - & - \\
\hline $\mathrm{Ti}$ & - & - & - & 0.900 & - & - \\
\hline $\mathrm{Cl}$ & - & - & - & - & 0.001 & - \\
\hline $\mathrm{Ba}$ & - & - & - & - & 1.519 & - \\
\hline $\mathrm{Ni}$ & - & - & - & 0.0003 & 0.004 & - \\
\hline $\mathrm{Sr}$ & - & - & - & - & 0.065 & - \\
\hline $\mathrm{Cr}$ & - & - & 0.005 & - & - & - \\
\hline B & - & - & 0.046 & - & - & - \\
\hline
\end{tabular}

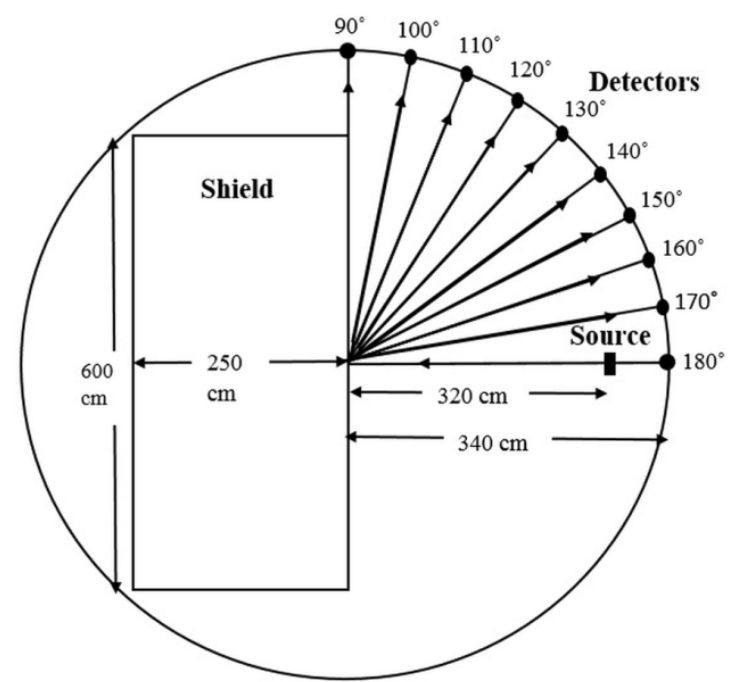

Figure 1. Schematic representation of the simulated geometry used for Monte Carlo calculations.

${ }^{1}$ Bashter (1997), ${ }^{2}$ Waly and Bourham (2015), ${ }^{3}$ Mortazavi et al (2010), ${ }^{4}$ Abdo (2002),

${ }^{5}$ Akkurt et al (2005), ${ }^{6}$ Hubbell and Seltzer (1995).

\section{Methods and Materials}

In this study, the MCNPX MC code (version 2.7.E) was used for all simulations [18]. Cross-section library files for neutrons and photons including ENDF/B-VII and ENDF/B-VI data were used in the MC simulations. Five high-density concretes with the densities ranging from $5.11 \mathrm{~g} / \mathrm{cm}^{3}$ to $3.45 \mathrm{~g} / \mathrm{cm}^{3}$ and ordinary concrete with density of $2.3 \mathrm{~g} / \mathrm{cm}^{3}$ were studied in our simulations $[2,3,6,19]$. The compositions of the studied concretes are shown in Table 1. The simulated geometry is shown in Figure 1. In this geometry, a concrete wall with the thickness of $250 \mathrm{~cm}$ and an area of $600 \times 600 \mathrm{~cm}^{2}$ was simulated. A circular plate as a source of photons and neutrons with $2 \mathrm{~cm}$ in diameter was located at $320 \mathrm{~cm}$ away from the concrete wall. In the first run, the photon beam spectra of 4 and $18 \mathrm{MV}$ Varian Linac reported by Sheykh-Bagheri was used as a photon source [20] (Figure 2). Ten spheres with a diameter

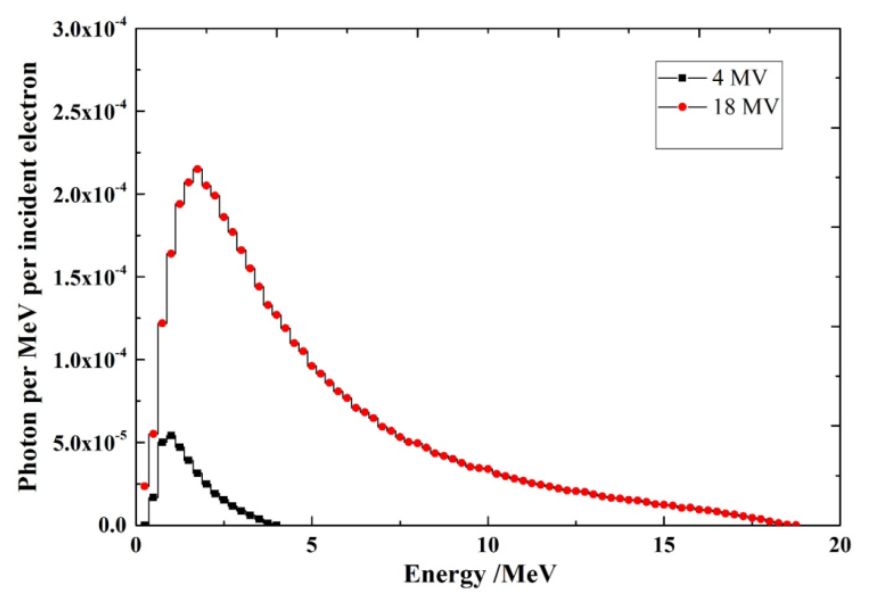

Figure 2. The spectra of $4 \mathrm{MV}$ and $18 \mathrm{MV}$ photon beams of Varian Linac used for MC calculations. of $6 \mathrm{~cm}$ at distance of $340 \mathrm{~cm}$ from the concrete wall at angles of $90,100,110,120,130,140,150,160,170$ and 180 degree were located as the detectors to calculate the fluence of photons scattering from the concrete wall. The F4 tally was used for calculation of fluence of photon reflected in each detector cell. The F4 tally is a photon, electron and neutron tally and calculates flux averaged over a cell in terms of $\mathrm{n} / \mathrm{cm}^{2}$ the MCNP code. In the second run, the photon source was replaced with photoneutron spectra of clinical linear accelerator which was reported previously for $18 \mathrm{MV}$ photon beam [16] (Figure 3). Then with F4 tally, fluence of neutron scattered from concrete walls was calculated in detector cells. In this simulation, fluence of photon and neutron scattered from each of six HDC in different angles was calculated.

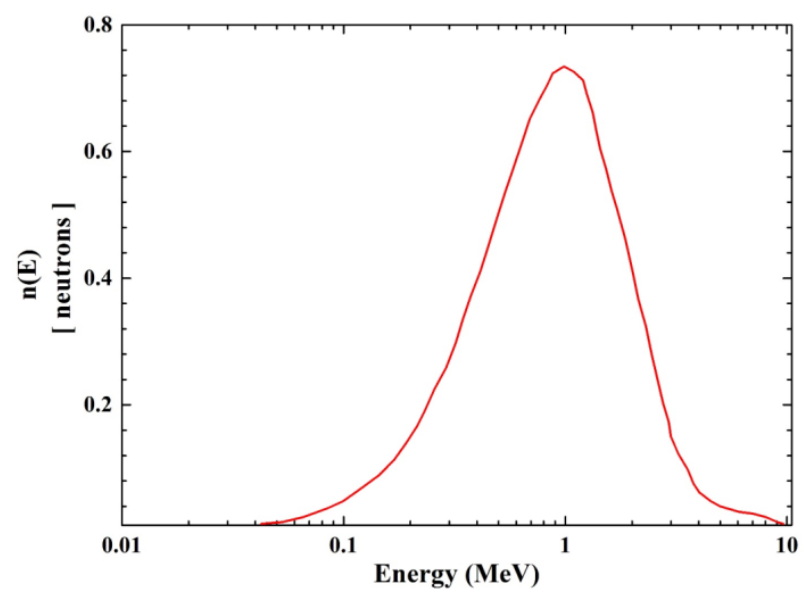

Figure 3. Neutron energy spectra produced from a $18 \mathrm{MV}$ photon beam of Varian linac used as a neutron source in the current study. 


\section{Results and discussion}

In Figure 4 the fluence of scattered photons per initial incident photon on the concrete wall with a thickness of $250 \mathrm{~cm}$ has been depicted from 90 to 180 degrees with interval of 10 degree. The incident photon spectra pertained to $4 \mathrm{MV}$ photon beam of Varian linac. The detectors were defined so that they score the photons coming from the wall. Overall, the ordinary concrete showed higher scattered fluence in all studied degrees and Datolite-Galena concrete $\left(4.42 \mathrm{~g} / \mathrm{cm}^{3}\right)$ had the lower scattered photons among all studied concretes. Another point that can be deduced from Figure 4 is that the fluence of scattered photons varies considerably for ordinary concrete and is decreased gradually from 90 to 180 degree. In other words, the photon fluence in 90 degree becomes approximately 1.8 times higher than photon fluence in 180 degree. Nonetheless, for other HDCs the scattered photon fluence remains constant or varies slightly with scattering angle. Among the studied heavy concretes, the barite lowered the fluence of scattered photons (1.6 times) with increase in the scattering angle. Conversely, the steel-magnetite increased the photon fluence (1.3 times) with scattering angle from 90 to 180 degree.

As long as the mass density matters, the results indicate that a larger part of incident photons are absorbed inside the HDCs compared to ordinary concrete so the smaller part are scattered in different angles. On the other hand, atomic composition is another factor that affects the fluence of scattered photons among concretes. For instance consider two concretes of Magnetite-Lead $\left(4.64 \mathrm{~g} / \mathrm{cm}^{3}\right)$ and Datolite-Galena $\left(4.42 \mathrm{~g} / \mathrm{cm}^{3}\right)$. Although they have very close mass densities and the Magnetite-Lead is heavier but the Datolite-Galena has less scattered photons because of its higher Lead content compared to magnetite-lead concrete. It can be concluded that the mass density and atomic composition of heavy concretes are the influencing parameters in their photon scattering properties. Concretes with higher mass density and enriched with high atomic number atoms exhibit lower fluence for scattered photons.

Figure 5 shows the reflected photon fluence per incident photon in terms of scattering angle for $18 \mathrm{MV}$ photon beam spectra derived from Varian Linac. The fluence of scattered photons per angle is somewhat similar to $4 \mathrm{MV}$ photons. However, for ordinary concrete, the fluence is dropped sharply by angle (about 2.2 times) which shows larger change for 18 MV compared to $4 \mathrm{MV}$ photons. The fluence of scattered photons with angle varies in a similar pattern with $4 \mathrm{MV}$ but the fluence variation with angle is slightly more pronounced for $18 \mathrm{MV}$ relative to $4 \mathrm{MV}$ photons. The lowest fluence of scattered photon is seen for Datolite-Galena and the highest scattered photons has been scored for Ilmenite-Ilmenite concrete among studied concretes. This can be attributed to the fact that the Ilmenite-Ilmenite concrete has the lowest mass density and also it contains $\mathrm{Fe}$ (atomic number $=26$ ) and $\mathrm{Ti}$ (atomic number $=22)$ atoms.

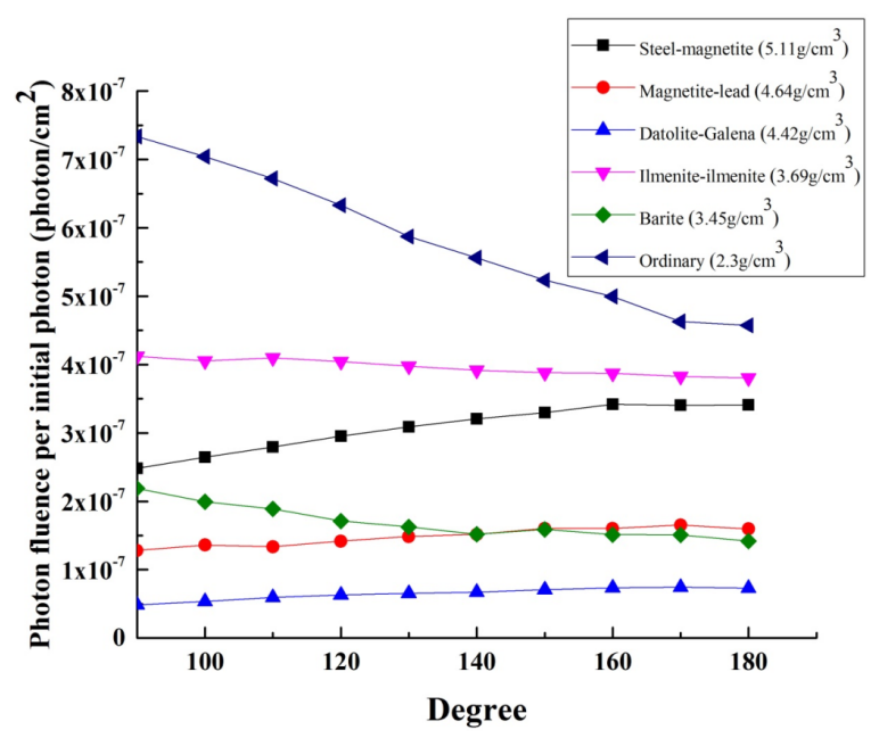

Figure 4. Scattered photon fluence variation with angle for a 4 MV photon beam of Varian Linac.

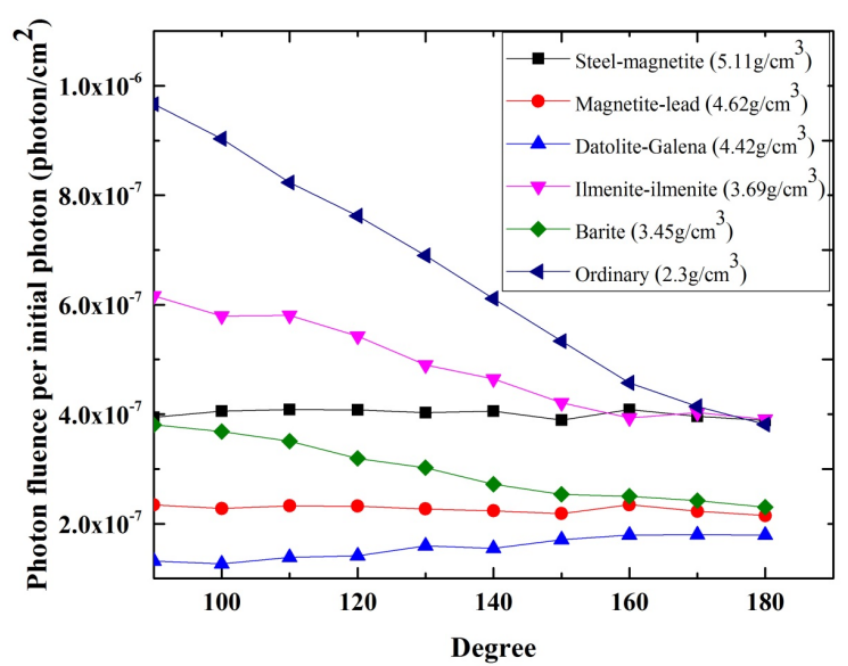

Figure 5. Scattered photon fluence variation with angle for a 18 MV photon beam of Varian Linac

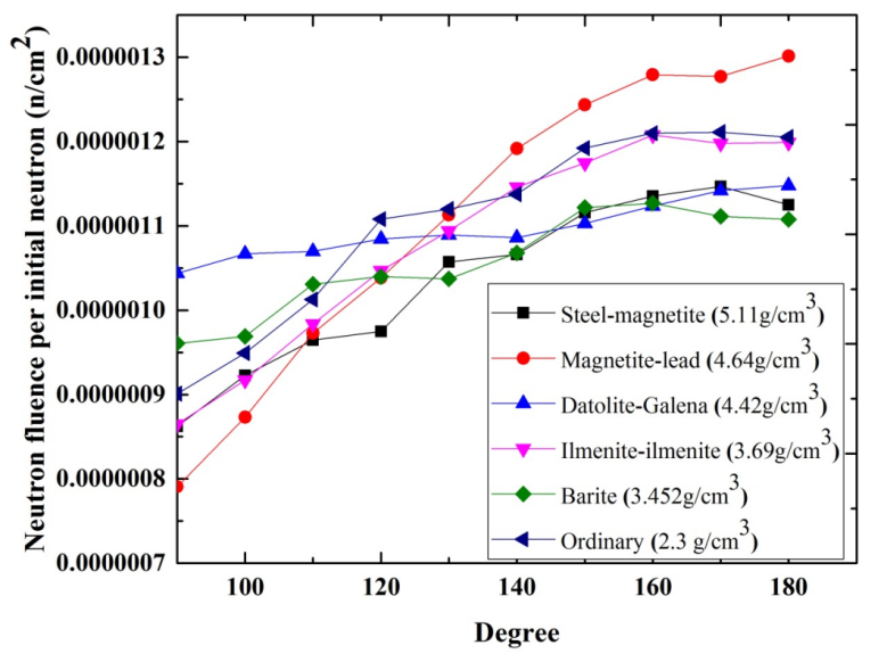

Figure 6. Scattered neutron fluence variation with angle for photon neutron spectra produced by a $18 \mathrm{MV}$ photon beam of Varian Linac. 
Neutron scattering by heavy concretes has been shown in Figure 6. The scattering of neutrons by concrete wall is completely different from photon scattering. As it can be shown in Figure 6, the scattering of neutrons is increased with angle from 90 to 180 degree and the highest increase (1.6 times) occurs for magnetite-lead concrete while the least variation is seen for Datolite-Galena concrete and the scattering is slightly increases with angle. The fluence of scattered neutrons is raised with angle and the highest scattering happens at 180 degree for all concretes. It should be point out here that the increase in fluence is reached to a plateau almost at 150 degree for all concretes. Also, in some of them it starts to go down after 150 degree such as barite and steel-magnetite.

Compton scattering is the prominent type of interactions between concrete walls and high energy photons used in radiation therapy facilities. For photons used in linac-based radiation therapy 4-18 $\mathrm{MeV}$, Compton scattering and pair production is the main cause of scattering. Since the concrete is a mixture of different atoms, the overall scattering in different angles and number of scattered photons will be the combination of all atoms scattering properties which making the concrete. Moreover, the probability of scattered photons produced by pair production will make the explanation and prediction of photon scattering from concrete walls very complex and sophisticated issue. In the current study the macroscopic behavior of scattered photons by HDCs revealed that the presence of atoms with high atomic number and higher mass density will cause significant reduction in the number of scattered photons in all directions with a slight but nonnegligible dependence on scattering angle. There was no comparable study in the literature on this regard. However, our finding was in accordance with results of similar studies $[10,16,19,21]$.

In a similar study by Facure et al on the neutron scattering properties of ordinary, barite concretes and wood barriers it was reported that less neutrons was scattered by barite concrete relative to ordinary concrete [22]. Our results were in agreement at scattering angle larger than 120 degree and maximum discrepancy was seen at 180 degree. They also showed that the mean energy of the scattered neutrons was not dependent on the scattering angle, as we found a negligible difference between the mean energy of scattered neutrons for studied angles.

In study by Mesbahi et al on the HDCs, the neutron scattering was calculated with a similar geometry and their results can be compared with our results at 180 angle [16]. Their results showed that the reflected neutrons for Magnetitesteel was lower than Datolite-galena and ordinary concretes. Additionally, the ordinary concrete showed higher reflected neutron fleunce than high density concretes. Our results are in agreement with their reported results [16].

The fluence of scattered neutrons varied with concrete composition and reflection angle. This discrepancy stems from the fact that there are different neutron-neutron elastic and inelastic cross-sections for atoms constitute the studied HDC concretes. Studies attributed this difference in the reflected neutron fluence to the $\mathrm{H}$ content in different concretes and the neutron-neutron interaction cross-sections of other major components such as $\mathrm{SiO}_{2}[15,16]$.

\section{Conclusions}

The photon and neutron scattering by different concretes used in construction of radiation therapy bunkers were calculated by using MCNPX MC code. The results revealed different fluence of scattered photons for HDCs with a slight dependence on reflection angle. However, for ordinary concrete the fluence differed with angle considerably. For neutrons, there was also a difference in the fluence of scattered neutrons in reflected angles based on their composition. And the Datolite-Galena concrete showed minimum dependency on angle while for magnetite-lead the variation in the fluence was the highest.

The information provided by the current research can be utilized in the design of radiation therapy bunkers built by using different HDCs. It will help the designers to precisely predict the neutron fluence inside the maze and entrance door.

\section{Acknowledgment}

This study was conducted as a part of Msc thesis for Medical Physics under financial support of immunology research center of Tabriz University of Medical Sciences.

\section{References}

[1] Aghamiri SMR, Mortazavi SMJ, Mosleh Shirazi MA, et al. Production of a novel high strength heavy concrete using tourmaline and galena for neutron and photon radiation shielding. Int J Radiat Res. 2014;12(3):277-282.

[2] Akkurt I, Basyigit C, Kilincarslan S, Mavi B. The shielding of gamma-rays by concretes produced with barite. Prog Nucl Energy. 2005;46(1):1-11.

[3] Bashter II: Calculation of radiation attenuation coefficients for shielding concretes. Ann Nucl Energy. 1997;24(7):1389-1401.

[4] Hadad K, Majidi H, Sarshough S. Enhanced radiation shielding with galena concrete. Nucl Technol Radiat Prot. 2015;30(1):70-74.

[5] Mesbahi A, Alizadeh G, Seyed-Oskoee G, Azarpeyvand AA. A new barite-colemanite concrete with lower neutron production in radiation therapy bunkers. Ann Nucl Energy. 2013;51:107-111. 
[6] Mortazavi SMJ, Mosleh-Shirazi MA, Maheri MR, et al Production of an economic high-density concrete for shielding megavoltage radiotherapy rooms and nuclear reactors. Int J Radiat Res. 2007;5(3):143-146.

[7] Mortazavi SMJ, Mosleh-Shirazi MA, Roshan-Shomal P, et al. High-performance heavy concrete as a multi-purpose shield. Radiat Prot Dosimetry. 2010;142(2-4):120-124.

[8] Mortazavi SMJ, Mosleh-Shirazi MA, Baradaran-Ghahfarokhi M, et al. Production of a datolite-based heavy concrete for shielding nuclear reactors and megavoltage radiotherapy rooms. Iranian J Radiat Res. 2010;8(1):11-15.

[9] Singh K, Singh S, Singh SP, et al. Gamma radiation shielding and health physics characteristics of diaspore-flyash concretes. J Radiol Prot 2015;35(2):401-414.

[10] Un A, Demir F. Determination of mass attenuation coefficients, effective atomic numbers and effective electron numbers for heavyweight and normal-weight concretes. Appl Radiat Isot. 2013;80:73-77.

[11] Ghiasi H, Mesbahi A. Sensitization of the analytical methods for photoneutron calculations to the wall concrete composition in radiation therapy. Radiat Meas. 2012;47(6):461-464.

[12] Ghiasi H, Mesbahi A. Gantry orientation effect on the neutron and capture gamma ray dose equivalent at the maze entrance door in radiation therapy. Nucl Technol Radiat Prot. 2012;27(1):70-74.

[13] Ghiasi H, Mesbahi A. A new analytical formula for neutron capture gamma dose calculations in double-bend mazes in radiation therapy. Rep Pract Oncol Radiother. 2012;17(4):220-225.

[14] El-Sayed Abdo A. Calculation of the cross-sections for fast neutrons and gamma-rays in concrete shields. Ann Nucl Energy. 2002;29:1977-1988.

[15] Facure A, Silva AX, Rivera JC, Falcão RC. Neutron scattering in concrete and wood: Part II - Oblique incidence. Radiat Prot Dosimetry. 2008;128(3):367-374.

[16] Mesbahi A, Azarpeyvand AA, Shirazi A. Photoneutron production and backscattering in high density concretes used for radiation therapy shielding. Ann Nucl Energy. 2011;38(12):2752-2756.

[17] Khaldari R, Mesbahi A, Kara U. Monte Carlo calculation of shielding properties of newly developed heavy concretes for megavoltage photon beam spectra used in radiation therapy. Iranian J Med Phys. 2016;13(4):250-260.

[18] Pelowitz DB, Durkee JW, Elson JS, et al. MCNPX 2.7.E Extensions. LA-UR-11-01502. Los Alamos National Laboratory; 2011.

[19] Waly ESA, Bourham MA. Comparative study of different concrete composition as gamma-ray shielding materials. Ann Nucl Energy. 2015;85:306-310.

[20] Sheikh-Bagheri D, Rogers DWO. Monte Carlo calculation of nine megavoltage photon beam spectra using the BEAM code. Med Phys. 2002;29(3):391-402.

[21] Mesbahi A, Azarpeyvand AA, Khosravi HR. Does concrete composition affect photoneutron production inside radiation therapy bunkers? Jpn J Radiol. 2012;30(2):162-166.

[22] Facure A, Silva AX, Falcão RC, Crispim VR. Neutron scattering in concrete and wood. Radiat Prot Dosimetry. 2006;119(1-4):514517. 